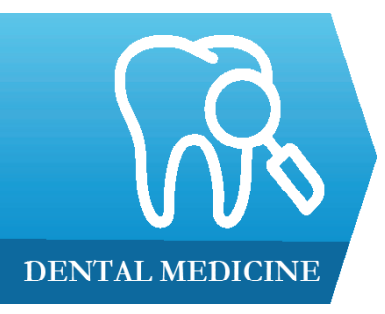

1) Department of Oral and Maxillofacial Pathology, Vivekanandha Dental College for Women, Tamilnadu, India

2) Vivekanandha Dental College for Women, Tamilnadu, India

\title{
Evaluation of DNA damage in tobacco associated human buccal cells using comet assay
}

Shanmugam Mohanapriya ${ }^{1}$, Thangadurai Maheswaran ${ }^{1}$, Nalliapan Ganapathy ${ }^{1}$, Thukanayakanpalayam Ragunathan Yoithapprabhunath ${ }^{1}$, Janardhanam Dineshshankar ${ }^{1}$, Vadivel Ilayaraja ${ }^{1}$, Rachel Sarah Vinodhini², Renuga Devi ${ }^{2}$

\begin{abstract}
Aim and objective. To assess the DNA damage in tobacco associated human buccal cells using comet assay.

Methods. The study included 75 study subjects, which were divided into 3 groups on the basis of tobacco usage. Group I - 25 individuals with no history of tobacco usage, Group II - 25 individuals with tobacco usage but without oral lesions and Group III - 25 individuals with tobacco associated oral lesions. Cytological smears collected from these individuals were used to assess the tobacco associated DNA damage by measuring the tail length in the comet assay method.

Results. The average tail length was found to be $1.46 \mu \mathrm{m}$ in the normal mucosa, 2.86 $\mu \mathrm{m}$ in tobacco users without oral lesions, $3.86 \mu \mathrm{m}$ in the lesional sites of tobacco users and $3.67 \mu \mathrm{m}$ in the non-lesional sites of these individuals. Factors like age, gender, duration and different forms of tobacco habit had their own impact on the oral mucosa.

Conclusion. Comet assay helps assess the subclinical genetic changes of oral mucosa even before the clinical manifestations of the precancerous lesions appeared due to tobacco usage. Thus, comet assay may bloom out as a novel adjuvant tool for the prevention of oral cancer in the near future.
\end{abstract}

Keywords: comet assay, DNA damage, tobacco

\section{Introduction}

Globally, the use of tobacco continues to be the leading preventable cause of death [1]. The burden of disease and death that tobacco imposes on public health is extensive [2]. Diagnosis of potentially malignant disorders prevents the occurrence of oral cancer but also helps in improving the survival of those who develop it [3].

Deoxyribonucleic acid is one of the key victims of many carcinogens. Since buccal epithelial cells have direct contact with the carcinogens during the tobacco usage, the identification of DNA damage in these cells would be useful and appropriate [4]. Very few published reports are available in the literature regarding the use of comet assay in the buccal epithelial cells and no studies were reported to compare the DNA damage using comet assay between the lesional and the non-lesional sites of tobacco users.

\section{Methods}

Study population was carefully selected and clinical data sheets were used to elicit the history and to record the details of age, gender, duration, frequency and forms of tobacco usage from each study participant. The sampling method and the importance of the study were explained in detail to the subjects. The study samples were collected from the volunteers after obtaining their informed consent. Institutional Ethical Committee approval was obtained with the reference number VDCW/IEC/09/2015 on 14.12.2015. The study group included: 
Group I - 25 individuals with no history of tobacco usage.

Group II - 25 individuals with tobacco usage but without oral lesions.

Group III - 25 individuals with tobacco associated oral lesions.

In Group I and Group II, buccal smear was taken from one side of the oral mucosa, whereas in Group III two sets of smears were taken. The buccal smear from the lesional site of the individual with tobacco-associated oral lesion was labeled as Group III-a, whereas the buccal smear from the non lesional site of the individual with tobacco associated lesion was labeled as Group III-b. Samples were obtained by scrapping the cells from the buccal mucosa using a small blunt wooden stick. The samples were then stirred in the phosphate buffered saline contained in Eppendorf Tubes and placed in the refrigerator at $4^{\circ} \mathrm{C}$ until processing.

The samples were then centrifuged (REMI Laboratory 8C Centrifuge, India) at $3500 \mathrm{rpm}$ for 5 minutes to get a cell suspension. The frosted slides used for placing the samples were wiped with alcohol to make the surface dust free and placed in the incubator (Thermo-fisher scientific incubator, U.S.) at $37^{\circ} \mathrm{C}$ for 30 minutes. The slides were pre-coated with normal melting point agarose (A9639-Sigma Aldrich, United States). The slides were then placed in the room temperature for 15-20 minutes until a clear homogenous layer was seen [5].

The sample was prepared with the low melting point agarose (RM861-HI MEDIA, India). Low melting point agarose was prepared by dissolving 0.5 grams of agarose in $12.5 \mathrm{ml}$ of phosphate buffered saline. The mixture was placed in the boiling water and allowed to cool for 15-20 minutes. $85 \mu \mathrm{l}$ of the low melting point agarose was then mixed with $10 \mu \mathrm{l}$ of the sample using the micropipette in a plastic tube. The suspension was then mixed using mechanical vibrator. From this suspension, $10 \mu$ l of the sample was placed on the slide and covered with a coverslip. The slides were then placed in the refrigerator at $4^{\circ} \mathrm{C}$ for solidification. After 3-4 minutes of solidification of the agar, the coverslip was lifted up and removed from the slides [5].

After the solidification of the sample, slides were gently placed in the lysis buffer for $1 \mathrm{hr}$ at 4 degree Celsius in a refrigerator. After lysis, the next step was preelectrophoresis to allow the unwinding of DNA. The slides were placed in the electrophoresis alkaline solution for about 30 minutes [5].

The slides were then removed from the lysing solution and placed in a horizontal electrophoresis system (BIORAD-ELECTROPHORESIS SYSTEM, Sub gel GT with power pack- HERCULES, CALIFORNIA,) near the anode end, sliding them as closely as possible. Next for the pre-electrophoresis process, the slides were left undisturbed in the electrophoresis tank without switching on the power supply for about 20 minutes.

Electrophoresis is one of the important steps in comet assay. During the electrophoresis, broken DNA fragments tend to migrate towards anode. The shorter DNA fragments travel the farthest. After pre-electrophoresis, electrodes were connected to the power-pack unit. At constant current, voltage of 24 volt and $300 \mathrm{~mA}$ was set for 15 minutes. The slides were then coated drop wise with neutralization buffer and left for 10 minutes. After neutralizing the $\mathrm{pH}$, the slides were drained and staining with ethidium bromide (SigmaAldrich, United States), a fluorescent dye was done by adding $50 \mu 1$ of the working solution of ethidium bromide to the slides. The excess staining liquid was blotted off [5]. The slides were then visualized using Olympus CX 31 fluorescence microscope, Japan with Binocular $30^{\circ}$ inclined and rotatable $360^{\circ}$ at $400 \mathrm{X}$ magnification and the fluorescent image was captured using Jenoptik ProgRes SpeedXT Core 3 CCD Microscope Camera - Germany.

The captured image was then measured using the ProgRes $^{\circledR}$ Capture Pro 2.8.8 Jenoptik software. After capturing the image, cells with well stained nuclei were included for counting. Cells with irregular staining, artifacts and unclear images were excluded. A total of 25 cells per sample were taken for counting. After calibrating the software, the length and the diameter of the nucleus was measured using the line tool and recorded in the Microsoft excel sheet. The tail length was obtained by subtracting the diameter from the total length of the nucleus. The mean tail length of the group was assessed from the values of 25 individuals. All the demographic data like age, sex, history and the duration of tobacco usage with average tail length were tabulated to assess the mean tail length. Statistical significance was assessed using Statistical Package for Social Science (SPSS) software version 17.

The mean tail length of the non-smokers, smokers without lesion and tobacco associated lesions was analyzed using the ANOVA (Analysis of variance) test. The level of significance $(P<0.05)$ was employed in all statistical comparisons. The difference between various groups was confirmed by the Post-Hoc test. The student $t$ test was used to compare the mean tail length between each group. The average tail length was also compared with age, gender, history of tobacco usage and the type of lesion for any possible statistically significant association.

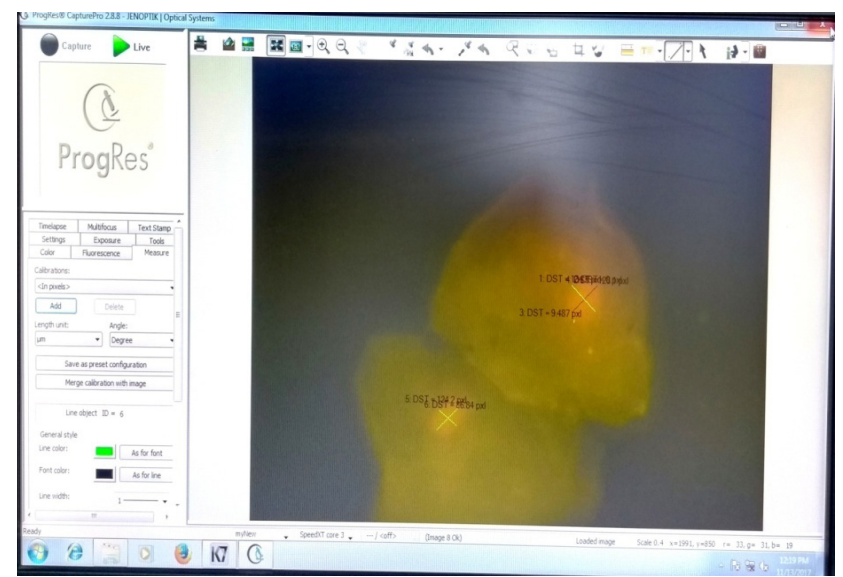

Figure 1. ProgRes Image analysis. 


\section{Dental Medicine}

\section{Results}

Comet assay was done to assess the DNA damage for the three groups of individuals; each group had 25 study participants. Out of the 75 individuals participating in this study, 31 were females and 44 were males.

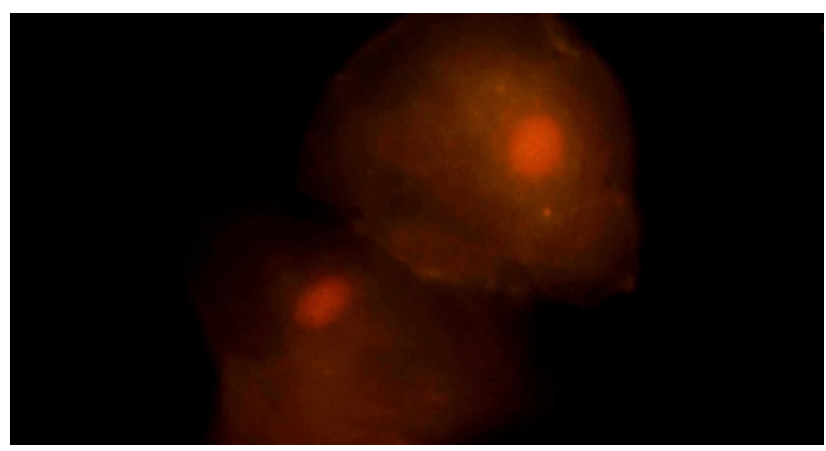

Figure 2. The microscopy of Group I in ethidium bromide staining in 40x magnification.

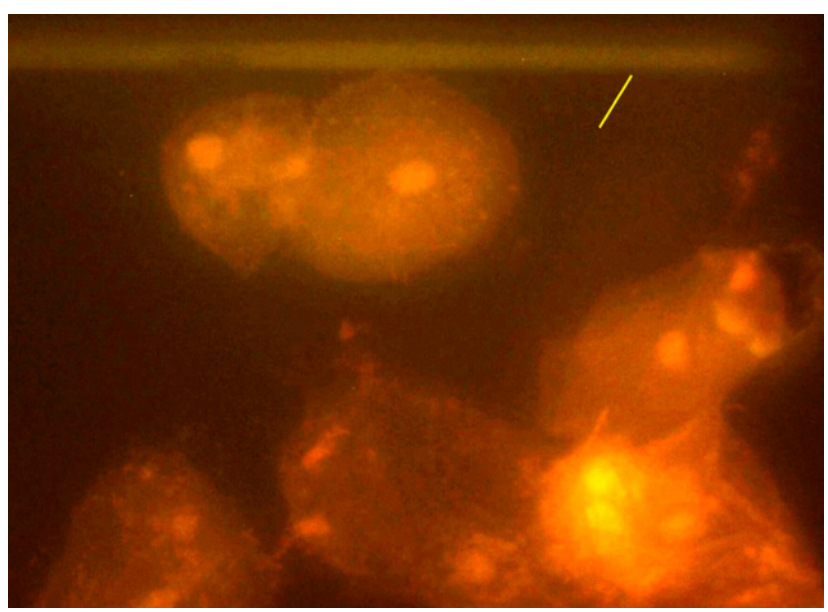

Figure 3. Microscopic view of Group I at 40x magnification.

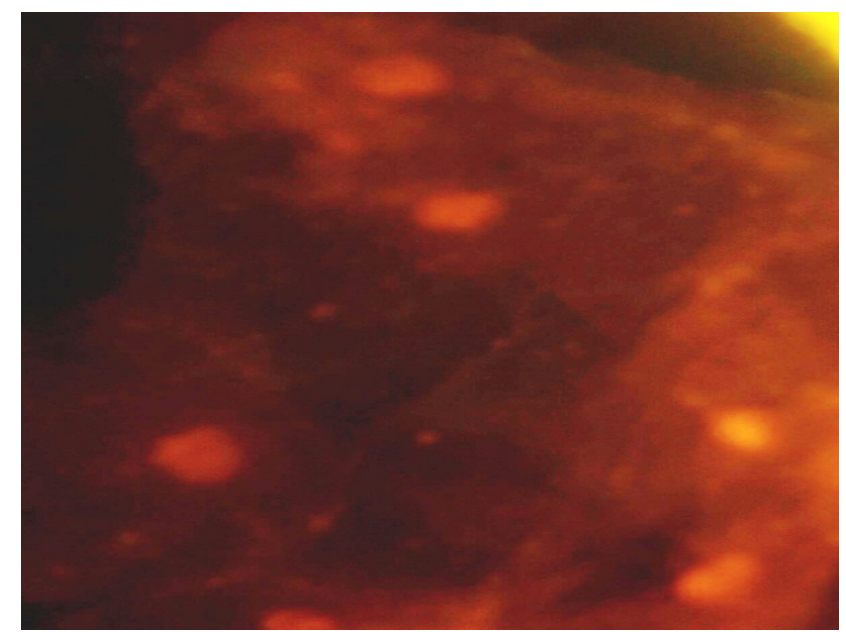

Lesional site

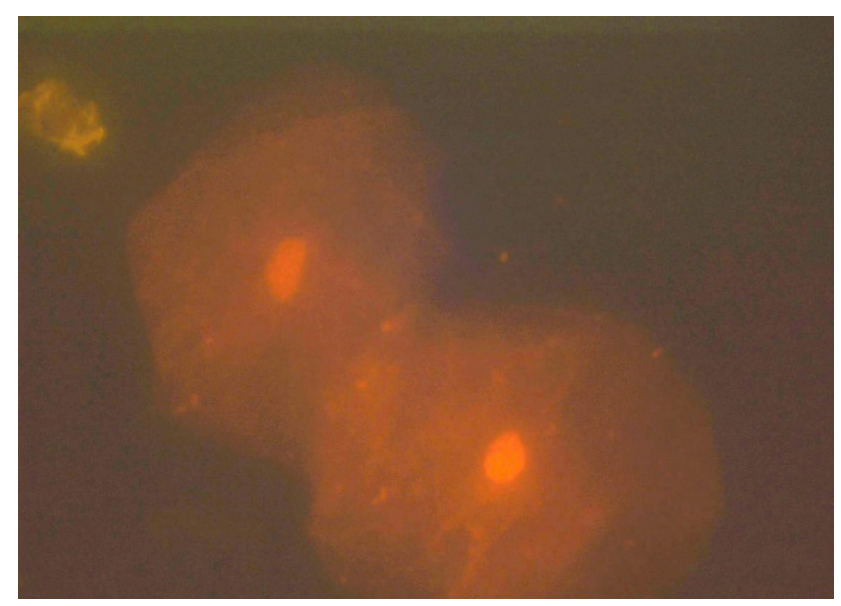

Non- lesional site

Figure 4. Microscopic fluorescent image of Group III in the lesional and the non-lesional site.

Table I. Comparison of the average tail length and standard deviation.

\begin{tabular}{|c|c|c|c|c|c|}
\hline \multirow{2}{*}{ Group } & \multirow{2}{*}{$\mathbf{N}$} & \multicolumn{2}{|c|}{ Average Tail length ( $\mu \mathrm{m})$} & \multirow{2}{*}{ ANOVA } & \multirow{2}{*}{ p } \\
\hline & & Mean & SD & & \\
\hline Group I & 25 & 1.46 & 0.35 & \multirow{5}{*}{148.98} & \multirow{5}{*}{$<0.001 * *$} \\
\hline Group II & 25 & 2.16 & 0.37 & & \\
\hline Group IIIa & 25 & 3.86 & 0.57 & & \\
\hline Group IIIb & 25 & 3.67 & 0.57 & & \\
\hline Total & 100 & 2.79 & 1.12 & & \\
\hline
\end{tabular}

Table II. The comparison of differences between average tail lengths between various groups.

\begin{tabular}{ll|l|c|c|c|c} 
& Group & N & Mean & SD & t & p \\
& Group I & 25 & 1.46 & 0.35 & 6.92 & $<0.001 * *$ \\
Average Tail length $(\mu \mathrm{m})$ & Group II & 25 & 2.16 & 0.37 & & \\
& Group II & 25 & 2.16 & 0.37 & 12.41 & $<0.001 * *$ \\
Average Tail length $(\mu \mathrm{m})$ & Group IIIa & 25 & 3.86 & 0.57 & & $<0.001 * *$ \\
& Group II & 25 & 2.16 & 0.37 & 11.09 & \multirow{2}{*}{ Average Tail length $(\mu \mathrm{m})$} \\
& Group IIIb & 25 & 3.67 & 0.57 & & 0.268 \\
Average Tail length $(\mu \mathrm{m})$ & Group IIIa & 25 & 3.86 & 0.57 & 1.12 &
\end{tabular}


Table III. Average tail length with the type of lesion in Group III-a (lesional site).

\begin{tabular}{|c|c|c|c|c|c|}
\hline Group IIIa & \multirow{2}{*}{$\mathbf{N}$} & \multicolumn{2}{|c|}{ Average Tail length $(\mu \mathrm{m})$} & \multirow{2}{*}{ ANOVA } & \multirow{2}{*}{$\mathbf{p}$} \\
\hline Type of the lesion & & Mean & SD & & \\
\hline Leukoplakia & 8 & 4.22 & 0.52 & \multirow{5}{*}{4.69} & \multirow{5}{*}{$0.012 *$} \\
\hline Smokers palate & 7 & 4.05 & 0.43 & & \\
\hline Squamous cell carcinoma & 2 & 3.35 & 0.49 & & \\
\hline Tobacco pouch keratosis & 8 & 3.45 & 0.46 & & \\
\hline Total & 25 & 3.86 & 0.57 & & \\
\hline
\end{tabular}

Table IV. The variation in average tail length with the type of lesion in Group III-b (non- lesional site).

\begin{tabular}{l|c|c|c|c|c} 
Group IIIb & \multirow{2}{*}{$\mathbf{N}$} & \multicolumn{2}{|c|}{ Average Tail length $(\boldsymbol{\mu m})$} & \multirow{2}{*}{ ANOVA } & \multirow{2}{*}{$\mathbf{p}$} \\
\cline { 1 - 2 } Type of the lesion & & Mean & SD & & \\
\hline Leukoplakia & 8 & 4.02 & 0.54 & \multirow{2}{*}{5.07} & $0.008^{* *}$ \\
Smokers palate & 7 & 3.90 & 0.46 & & \\
Squamous cell carcinoma & 2 & 3.07 & 0.06 & & \\
Tobacco pouch keratosis & 8 & 3.28 & 0.42 & \\
Total & 25 & 3.67 & 0.57 &
\end{tabular}

Table V. Forms of tobacco usage and average tail length in Group-II.

\begin{tabular}{l|c|c|c|c|c} 
Group II & \multirow{2}{*}{$\mathbf{N}$} & \multicolumn{2}{|c|}{ Average Tail length $(\boldsymbol{\mu m})$} & \multirow{2}{*}{ ANOVA } & p \\
\cline { 1 - 1 } \cline { 3 - 4 } Forms of tobacco & 6 & Mean & SD & & \\
Betel quid & 6 & 2.25 & 0.44 & 0.67 & 0.582 \\
Bidi & 5 & 2.21 & 0.30 & \\
Cigarette & 8 & 2.24 & 0.48 & \\
Pan & 25 & 2.16 & 0.31 & \\
Total & & & 0.37 &
\end{tabular}

Compared to the average tail length and the type of lesion, leukoplakia have much higher value of tail length than the other tobacco associated lesions in Group III-a.

Compared to the average tail length and the type of lesion, leukoplakia has relatively higher tail length than the other tobacco associated lesions in Group III-b, which is statistically significant.

When we compared the average tail length with the forms of tobacco usage in the individuals belonging to Group II, the average tail length of betel quid users and cigarette users have much higher value than the other forms of tobacco in Group II.

\section{Discussion}

Tobacco is one of the important etiological agents for various forms of diseases. The usage of tobacco leads to an array of oral lesions that have more potential for malignant transformation [6]. Non- lethal DNA damage is the heart of carcinogenesis and occurs due to environmental exposure of various agents in the body. The failure of DNA repair enzyme to control the DNA damage results in the uncontrolled proliferation and decreased apoptosis [7].

Most of the oral cancers are associated with exposure of tobacco and is usually preceded by visible clinical changes called precancerous lesions or potentially malignant disorders. Since there is limited information about the status of DNA damage in clinically normal buccal mucosa of tobacco users, this study was done with the objective of comparing the DNA damage between the lesional and non-lesional buccal cells of tobacco users with comet assay.

The results of our study emphasize that even in the absence of the tobacco habit every individual undergo some sort of DNA damage (Table I). This minimal level of DNA damage may be due to the various factors like environmental, occupational and age related factors [8]. The environmental conditions play a role in the accumulation of DNA damage. Similar studies also revealed that the age and environmental conditions contribute a great deal in setting a higher degree of basal DNA damage [9].

An in vivo autofluoroscence spectroscopic study was done in smokers and the non-smokers in the lymphocytes using comet assay. They also found that mean tail length of the smokers is considerably higher than that of the nonsmokers (Table II) [10].

The mean tail length was significantly higher in Group-III when compared to Group II, this may be attributed to difference in duration of the habit, genetic 
predisposition or the role of nutrition like anti-oxidant that may protect the tobacco users from DNA damage. In comparing the lesional and the non-lesional sites of the individuals in Group III we did not find a large difference (Table II). This depicts the concept that subclinical changes are found in the clinically normal mucosa of the lesional patient before it changes to a pre-cancerous lesion.

In comparing the DNA damage in the lymphocytes of the oral precancerous and cancerous patients, it was concluded that the mean tail length of leukoplakia was more than that of oral submucous fibrosis; oral cancer patients had much more increased tail length than the other two lesions [11].

It was found in a study that by assessing the DNA damage of the different staging of squamous cell carcinoma, the mean DNA damage of 30 controls were $0.8616 \mu \mathrm{m}$, whereas in our study it was $1.46 \mu \mathrm{m}$. They have compared the various grades of squamous cell carcinoma and the mean DNA damage was $3.874 \mu \mathrm{m}$ which was similar to results of our study in tobacco associated oral lesions of $3.86 \mu \mathrm{m}[5]$.

The comet assay was done in the affected gingival epithelial cells of oral submucous fibrosis patients and it was concluded that the mean DNA damage of the lesional site was $4.7 \mu \mathrm{m}$, where as in our study it was $3.86 \mu \mathrm{m}$. Just as in their study, in our study similar DNA damage of 1.49 $\mu \mathrm{m}$ was found in the control group [12].

A stepwise increase in DNA damage was found in different grades of dysplasia ranging from $0.31 \mu \mathrm{m}$ to 1.25 $\mu \mathrm{m}$ in leukoplakia patients. The similar increase in DNA damage was evaluated in our study ranging from $1.46 \mu \mathrm{m}$ to $3.86 \mu \mathrm{m}$ in normal and lesional patients [13].

When we compared the tail length between various tobacco associated lesions, leukoplakia patients were found to have more DNA damage than the patients with other tobacco associated lesions such as squamous cell carcinoma, tobacco pouch keratosis and smokers palate (Table III and IV). The review on the effect of tobacco on oral health emphasizes the concept that leukoplakia has more tendencies for malignant transformation than the other lesions like smokers' palate or tobacco pouch keratosis. A similar study which was done to compare the genetic damage in precancerous and cancerous patients, found leukoplakia to have relatively higher tail length than oral squamous cell carcinoma [14].

In correlating the forms of tobacco usage with the average tail length in Group-II, Betel quid users have much higher tail length than the other forms of tobacco usage (Table V). Naveen Kumar et al., found cigarette smoking to have much harmful effect than the other forms of tobacco usage [15]. In the study conducted among 300 individuals of various tobacco users Pan masala and Gutkha usage have more effect than smoking [16].

Nicotine addiction with usage of tobacco causes continual cigarette smoking and chronic exposure to carcinogens. The carcinogens can be metabolically activated to intermediates that react with DNA, forming DNA adducts. The metabolic detoxification of carcinogens leads to harmless excreted products. If the DNA adducts are repaired by cellular repair enzymes, DNA is returned to its normal undamaged state. But if the adducts persist during DNA replication, miscoding can occur, which leads to a permanent mutation in the DNA sequence. Cells with damaged or mutated DNA can be removed by apoptosis. If the mutations occur in particular regions of crucial genes, such as the RAS or MYC oncogenes or TP53 or CDKN2A tumor-suppressor genes, the result can be the loss of normal cellular growth-control regulation and tumor development. There will be increased angiogenesis and cellular development that leads to the progression of cancer [17].

The comet assay assesses a specific form of DNA damage - double strand and single strand breaks. Although, this study indicates that smokers may have more DNA breakage, we need to remember that this mere association does not prove causality. Previous studies investigating the mutation signature in various smoking related cancers particularly in tissues with direct exposure implicate point mutations particularly $\mathrm{C}>\mathrm{A}$ transversions as the main mutation signature and not necessarily DNA breaks [18].

The field of genetically altered cells in patients with squamous cell carcinoma called "field cancerization," has been documented with numerous clinical, histopathological and molecular studies. Therefore, the patients with head and neck squamous cell carcinoma are subject to the risk of developing local recurrences or second primary tumors as a consequence of the field cancerization, which is considered to be a bad prognostic sign. So it is important to evaluate the clinically normal mucosa of the lesional patients [19].

\section{Conclusion}

Early diagnosis and assessment of potentially malignant lesions will help prevent the malignancy at a much earlier stage. Many advanced molecular techniques are available to detect and assess these conditions. One such technique is the comet assay that can identify, assess and predict the prognosis of the subclinical genetic changes of oral mucosa even before the clinical manifestations of the potentially malignant lesions are visible. This potential noninvasive test can be used for convincing the individuals to quit tobacco usage even before the appearance of visible clinical changes. Therefore comet assay may bloom out as a novel tool for the prevention of oral cancer in the nearby future.

\section{References}

1. Berg CJ, Fong GT, Thrasher JF, Cohen JE, Maziak W, Lando $\mathrm{H}$, et al. The impact and relevance of tobacco control research in low-and middle-income countries globally and to the US. Addict Behav. 2018;87:162-168. 
2. Beck TN, Golemis EA. Genomic insights into head and neck cancer. Cancers Head Neck. 2016;1:1.

3. Glei M, Schneider T, Schlörmann W. Comet assay: an essential tool in toxicological research. Arch Toxicol. 2016;90:2315-2336.

4. Valverde M, del Carmen López M, López I, Sánchez I, Fortoul TI, Ostrosky-Wegman P, et al. DNA damage in leukocytes and buccal and nasal epithelial cells of individuals exposed to air pollution in Mexico City. Environ Mol Mutagen. 1997;30:147-152.

5. Bhagwath SS, Chandra L. Assessing extent of single stranded DNA damage in oral mucosal cells of patients with oral squamous cell carcinoma and its correlation with TNM staging. Indian J Dent Res. 2014;25:555-558.

6. Ganesh D, Sreenivasan P, Öhman J, Wallström M, Braz-Silva PH, Giglio D, et al. Potentially Malignant Oral Disorders and Cancer Transformation. Anticancer Res. 2018;38:3223-3229.

7. Raj L, Ide T, Gurkar AU, Foley M, Schenone M, Li X, et al. Selective killing of cancer cells by a small molecule targeting the stress response to ROS. Nature. 2011;475:231-234.

8. Møller P, Knudsen LE, Loft S, Wallin H. The comet assay as a rapid test in biomonitoring occupational exposure to DNAdamaging agents and effect of confounding factors. Cancer Epidemiol Biomarkers Prev. 2000;9:1005-1015.

9. Dixit AK, ARUN N. Assessment of Basal DNA Damage in Normal and Healthy Young Individuals by COMET Assay. J Biosci Tech. 2011;2:247-257.

10. Rajmohan M, Naidu RM, Thamaraiselvi D, M D. In Vivo Autofluorescence Spectroscopic Study and Evaluation of DNA Damage by Comet Assay in Smokers. J Clin Diagn Res. 2015;9:ZC16-ZC19.

11. Mukherjee S, Ray JG, Chaudhuri K. Evaluation of DNA damage in oral precancerous and squamous cell carcinoma patients by single cell gel electrophoresis. Indian J Dent Res. 2011;22:735-736.

12. Dodani K, Anumala N, Avula H, Reddy K, Varre S, Kalakonda BB, et al. Periodontal findings in patients with oral submucous fibrosis and comet assay of affected gingival epithelial cells. J Periodontol. 2012;83:1038-1047.

13. Vellappally S, Binmgren M, Huraib S, Hashem M, Patil S, Anil S. Assessment of DNA Damage in Leukoplakia Patients with Various Degrees of Dysplasia. J Contemp Dent Pract. 2015;16:971-976.

14. Katarkar A, Mukherjee S, Khan MH, Ray JG, Chaudhuri K. Comparative evaluation of genotoxicity by micronucleus assay in the buccal mucosa over comet assay in peripheral blood in oral precancer and cancer patients. Mutagenesis. 2014;29:325-334.

15. Naveen-Kumar B, Tatapudi R, Sudhakara Reddy R, Alapati S, Pavani K, Sai-Praveen KN. Various forms of tobacco usage and its associated oral mucosal lesions. J Clin Exp Dent. 2016;8:e172-e177.

16. Jyoti S, Khan S, Naz F, Rahul, Fahad A, Siddique YH. Assessment of DNA damage by panmasala, gutkha chewing and smoking in buccal epithelial cells using alkaline single cell gel electrophoresis. Egypt J Med Hum Genet. 2013;14:391-394.

17. Hecht SS. Tobacco carcinogens, their biomarkers and tobacco-induced cancer. Cancer. 2003;3:734-744.

18. Alexandrov LB, Ju YS, Haase K, Van Loo P, Martincorena I, Nik-Zainal S, et al. Mutational signatures associated with tobacco smoking in human cancer. Science. 2016;354:618622.

19. Curtius K, Wright NA, Graham TA. An evolutionary perspective on field cancerization. Nat Rev Cancer. 2018;18:19-32. 